\title{
The revelation(s) of Asher Levi: An iconographic literacy event as a tool for the exploration of fragmented selves in new literacies studies after $9 / 11$
}

\author{
Jeanine M. Staples
}

\begin{abstract}
This article considers the dynamics of an iconographic literacy event that functions as a tool for explorations of literacy practices and fragmented selves, particularly in relationship to the literate lives of marginalized individuals in the post 9/11 era. The author examines what happened when a group of 10 African American women in an urban area employed new literacies in the teaching/learning spaces of their personal lives (i.e. individual homes, familiar eateries, communicative digital technologies) to explore and respond to stories in post 9/11 popular culture narratives. The study employed ethnographic methods (interviews, journaling, email and instant message writing and critical observations) with members of the inquiry over the course of two years. The author investigated critically the meeting of biography, fiction and autoethnography as a literacy event used to couch the literacies and fragmented selves of these women in the post 9/11 era. Findings regarding the nature of their post 9/11 literacies, as expressed through fragmented selves, are shared, along with implications for new literacies research and teaching. Findings show that the women's post 9/11 literacies include a range and variation of critical sensibilities that include, but are not limited to, multiple levels of sociolinguistic integration, sociocultural criticality and heightened awarenesses.
\end{abstract}

Keywords: New Literacy Studies, African American women, media education, qualitative inquiry, 9/11

Please cite this article as:

Staples, J.M. (2011). The revelation(s) of Asher Levi: An iconographic literacy event as a tool for the exploration of fragmented selves in new literacies studies after 9/11. Qualitative Studies, 2(2): 79-97.

Is there any way of writing the "fragmented self"? That is, can we represent a conflicted identity, a self with multiple affiliations, a self that is transient, a self whose shape is contingent on the given contexts in which it emerges? (de Freitas \& Paton, 2009, p. 487).

The provocative questions posed above speak to the complexities within examinations of fragmented, evolving, socially situated selves. Recently, de Freitas and Paton (2009) employed this question and others to explore critically the ways a group of graduate students grappled with humanist and post-humanist stances for self-study through the methodology of autoethnography. They explained that autoethnography is positioned to "indicate how the researcher is implicated in the context of inquiry" and points to how we might resolve the conflict between the emergence, composition and presentation of a Humanist, ideal "I" and members' claims that they overcame such a presentation (p. 485). Specifically, de Freitas and Paton (2009) worked to understand empirically the ways students experienced a disjunctive or misrecognition of the self in the reflected self. In addition, they worked to understand the constitution of the elusive and transient ideal "I" as it was used and emerged within members' autoethnographic writing. They did so by maintaining 
particular interest in the ways members dealt with self-recognition and exploration through the genres of confession and testimony. Within this framework for data analysis, they presented a "collective biography" of members. This tactic was used to frame more particularly "the assemblage of ruminations on the nature of the self that were generated through questionnaire data" (de Freitas \& Paton, 2009, p. 487). They found that, ultimately, the dissonance and perplexities about self that members met within their writings were crucial to the development of meaningful conceptions of self over time, and further, that it is neither possible nor desirable to attempt to resolve this conflict (de Freitas \& Paton, 2009). Rather, they suggest that autoethnography functions as a methodological framework through which individuals can decenter the self as a knowing subject (Peters \& Burbules, 2004) and come to terms with the notion that "the time of the fiction of a single true, authentic self has come and gone" (Denzin \& Lincoln, 2000, p. 1060).

Subverting the idea that a "single true, authentic self" exists is useful to me as a qualitative researcher of literacies because it assists the social justice project upon which my work is founded. That is, eradicating the idea of a unified, stable identity supports an understanding of how and why marginalized individuals and groups read, write and respond to sociopolitical instances of local and global inequality, discrimination and propaganda communicated through and as popular culture narratives. When I say "marginalized" individuals and groups, I refer to those people who are socially, historically, culturally, and at times, linguistically "othered" - negated or made ancillary, strange, exotic, curious, misunderstood, disposable, or even dangerous in relation to the individual or group that is centralized. This fringe status bears power in that it can be framed with intellectual and spiritual passions, criticalities and creative nuances of expression that are evolved in order to transgress boundaries obstructing paths to the center. As a new literacies theorist, scholar and practitioner, I focus regularly on ways I can liberate and empower my methodological inquiries into the nature and utility of the contemporary literate lives of African American urban adolescents and adults in addition to other marginalized and often adversely labeled groups. My work hones in particularly on the ways marginalized individuals and groups' converging identities (such as race, gender, age, religious affiliation and socioeconomic status) intersect and are mediated via their literate lives and in relationship to popular culture narratives, particularly in modern times.

Members' literate lives include their literacy practices. Literacy practices are the socially situated, culturally informed, politically laden and media/technology influenced ways that people establish, destabilize and challenge epistemologies, share information, generate texts, communicate broadly, form (hyper)social networks, perform iterations of selves and engage in intellectual work for particular purposes (Marshall, Staples \& Gibson, 2009; Staples, 2008a, 2008b, 2008c, in press). The observable episodes and artifacts which arise from literacy practices, and are shaped by them, are literacy events (Barton \& Hamilton, 2000; Heath, 1982; Street, 1993). Such episodes may take the form of a written document, oral story, text-based discussion, photograph or digital composition. My work produces nuanced and evolving analytic responses to questions like "what happens when marginalized individuals and groups employ new literacies in various teaching/learning contexts?" Facilitating critical, deep explorations with respect to these phenomena often calls for the evolution of methodologies because the layers of selves employed provokes the intersections of voice, position, his/herstories, public/private consciousness, theology, art, cultural phenomenological movements, sociocultural vision and memory in addition to reading, writing, speaking and listening. 
To explore the intersections of new literacies, fragmented selves and the ways they can be framed through a new literacy event, I first discuss briefly the necessity of situating fragmented selves and literacy practices through a new literacy event. Second, I frame the inquiry presented here by relaying my research question, methods of data collection and the interpretive framework used to understand happenings in the inquiry. Then, I discuss the iconographic work used to couch literacy events and literacy practices that emerged among group members in relationship to particular social situations and consciousnesses. Next, I share artifacts from the inquiry and point to the ways members' literacies and fragmented selves advanced within it. Lastly, I present implications for new literacies research and teaching for the field in contemporary times.

\section{Situating fragmented selves and literacy practices through a new literacy event}

As an African American woman scholar/teacher, I feel compelled to consider deeply the constitution of fragmented selves, social situations and literate explorations. I do so as a testament to my devotion to qualitative inquiry into literate lives and the constituents I serve in addition to furthering my interests in converging phenomena as they occur in current literate lives. Autoethnography speaks both to the narrative nature of many of my inquiries, the social aspects of my sites for research, and the persistence of texts as phenomena to be studied and/or (re)produced within various teaching/learning contexts. It is also responsive to the cultural and linguistic nuances that one must regard and take up in order to mine experiences and personal evolutions. Ellis and Bochner (2000) described autoethnography as "systematic sociological introspection" whereby the researcher begins with personal feelings and memories and uses reflexive writing practices to move back and forth between personal narratives, encompassing contexts, and social forms" (Ellis \& Bochner, 2000, p. 735). This introspection yields a post-Humanist self, a site of dislocation, contradiction and instability which includes internal disorientation and fragmentation (St. Pierre, 1997, 2000). Such a struggle gives way to the autobiographical subject's striving toward "the false symmetry of... a unified self which can only ever be a fiction" (Anderson, 2001, p. 66). This "fiction of autobiography" is explored in artistic autoethnography (de Freitas \& Paton, 2009, p. 490). For example, Ellis (2004) wrote of her own work, "I think and gather information like an ethnographer, but I try to write like a novelist or story teller. Autoethnographic writing goes hand in hand with fictional techniques such as dialogue, scene setting and plot development" (p. 335).

Yet, regardless of its creative allowances, I have come upon a particular problem in my attempts to use this methodology to form creative analytic portraits of the ways marginalized individuals and groups employ literacies to engage the language, images and messages used in media texts, particularly when attempting to deal insightfully with the idea of fragmentation. The problem is two-fold. First, autoethnographic writing tends to emerge exclusively from the stance of the researcher. This vantage point can quiet the voices of members. One objective of my work is to challenge the rigidity of the margins and further center member's voices as primary, creative and knowledgeable. Second, the power of fiction, as a means through which qualitative researchers might (re)imagine and advance boundaries impeding interpretation and description of members' constructions of fragmented selves begs that autoethnographic writing yield an inventive stance. de Freitas and Paton (2009) used collective biography as a way to explore members' autobiographical ruminations on self. They found it to be a useful tactic because it allowed them to "blur boundaries of the individual self" by examining stories as they "evolve[d] into a collective statement about more general mechanisms of subjectification" (Davies et al., 2001, p. 169). However, this tactic 
functioned as a way to communicate the group's responses as a whole. It may not have been sufficient in scope to grapple with data that represented fragmentations of selves that one could trace across members' writings or discrepant cases that challenged dominant fragmentations. My struggle to capture the ways marginalized individuals use literacies in relationship to the narratives of popular culture includes a literacy event that fuses collective biography, autoethnography and a fictional (re)presentation of members. With regard to the study presented here, this fusion serves to push forward analysis, interpretation and description of ethnographic data collected immediately after 9/11. It is best described as an iconography and is discussed below. The data it contains feature various ponderings on the location and evolution of selves within competing discourses on words and signs perpetuated by media; inter-group rhetoric on the (de)stability and necessity of heterosexual romantic love and the ways it can function as a lens through which African American women understand the sociocultural situation and power of a Black Christian feminine self; the sociopolitical influence of religious thought and its impact on social and cultural ways of being and meaning making; in addition to language, images and the phenomenological junctions of the post 9/11 era.

\section{A post 9/11 inquiry: Research question, methods and interpretive framework}

During the first two years after 9/11, I became increasingly interested in the types of local, empirical frameworks that were developing in relationship to media representations of "Terror", the heinous instances of fear, intimidation and mayhem that incite negative national and global repercussions (i.e. a suicide bomber in Iraq or Afghanistan in the presence of native or allied troops and/or innocent civilians), and "terror", the type of private or personal instances of fear that incite negative local repercussions (i.e. a violent or mean-spirited transaction between lovers or friends, a web of gossip, lies, or interpersonal disassociation among friends or even those perceived to be strangers). When I say "local empirical frameworks" I refer to those complex ways of knowing that function at the site(s) of the individual fragmented self and are shared with members of a similarly situated community. To explore these frameworks I met with a group of ten (10) women twenty-two (22) times from 2003-2005. During gatherings, members responded to and shared ideas about various post 9/11 stories - popular culture narratives (PCNs) - that presented language, words, ideas and interpersonal scenarios about people's lives in the post 9/11 era. The "post 9/11 era" constitutes the time frame immediately after $9 / 11$ until the present. Other "eras" are conflated within this time frame. Some include the "Web 2.0 era" and the "social networking era". "Post 9/11 literacies" are the socially situated ways in which meaning is made and selves are dynamically represented within the era and in relationship to phenomena and languages storied within the era; and, "post 9/11 popular culture narratives" can be understood as the responsive, contradictory and interdependent media and personal stories that function as literacy events.

Popular culture narratives have five primary descriptors (Marshall, Staples \& Gibson, 2009; Staples, in press). First, PCNs portray nuances of social constructs. Race, class, gender, religion and sexuality are often at issue in them. Second, they often depict archetypes-representative human paradigms that embody "types" of identity. Third, these narratives frequently mingle standardized English and variations of English. This mingling affords characters, authors, or narrators the ability to texturize social situations and individuals in specific ways. Fourth, they produce or describe visual representations that signify and complicate language. That is, compositions of rich, moving and still images are depicted and invoked to pictorially translate what is expressed. Lastly, PCNs provoke readers to deeper revelations of predicaments of human conditions and the complexities of 
personhood, place, word and image. This provocation can be (and often is) initiated by both print and visual popular culture narratives. PCNs offer a point of entry into the literate lives of many marginalized groups because they are highly consumed, readily accessible and consistently (re)present, for study or entertainment, innumerable scenarios of various individuals, groups and lived experiences (both "real" and "contrived").

Women were chosen for the inquiry based on their responses to a simple question, "Do you think reading and writing can save your life?" All replied, "No." I asked this question because I experienced a history, as a literate person, scholar and teacher, which caused me to answer in the affirmative. I wanted to understand, through this question, how other African American women conceived the power of literacies and understood their capacity for facilitating inquiry, freedom, and relationships in everyday life. I found the common pessimism among the women interesting. I noted that it conflicted with my understanding of literacies and my assumptions about what formally educated adult women might believe about their power or influence as literate beings. As a result of this, I asked the women to come together to read and write and "make sense of the word and the world after 9/11" (Staples, Journal Entry, 01.09.03).

Members used journals, poems, email, IM correspondences and transcripts of group conversations to build community and develop intimate communication. The women were called group members instead of participants because neither the inquiry nor data collection was structured systematically. Instead, they progressed organically and intuitively. In addition, most data were shared, some co-authored and a number of them compiled to create composite artifacts to illustrate knowledge, questions, stances and perspectives relative to our selves and post 9/11 narratives. To inquire deeply and critically, I asked "what happens when a group of African American women in an urban area employ new literacies in the teaching/learning spaces of their personal lives (i.e. individual homes, familiar eateries, and communicative digital technologies) to explore and respond to post 9/11 popular culture narratives?" I employed a triangulated interpretive framework to analyze data.

\section{Interpretive Analytic Framework}

Critical black feminist frames allowed me to analyze the ways members' racialized and gendered selves were reified through literacy practices (Collins, 1990; hooks, 1989, 1992). Endarkened feminist epistemologies helped me to understand the ways members' racialized and gendered selves intersected a collective spiritual epistemological framework for knowing, action and leadership (Dillard, 2000). Critical literacies theory allowed me insight into the ways the women employed literacies and facilitated literacy events as ways to converse and build knowledge, particularly with various modes of communication. Analysis included the iterative and progressive processes of "collecting, noticing and thinking about" recurrent themes, rejoinders, stances and questions members had, particularly as these phenomena signified various types of emphases on and representations of selves, self positions and self evolutions in relationship to the messages of post 9/11 PCNs and/or other members (Siedel, 1998). Via multiple readings within and across data sets, I coded and classified these things.

Then, I logged themes with respect to the visibility, corroborations and contradictions of members' fragmented selves. Next, I interrogated ascending findings by introducing questions from each aspect of my triangulated framework within and across data sets, paying close attention to 
discoveries about fragmentation that seemed expected in addition to those that seemed uncommon, were confirmed and/or challenged by members. To interpret analyzed data and grapple with ways to describe findings, I draw from Haraway's (1988) notion of cyborg consciousness and situated knowledges. Haraway's work provides ways to think about the love/hate, trust/distrust relationship human beings have with machines and their promise to liberate, empower and unite; it also offers points of entry for pondering the idea that female embodiments inherently stimulate various metaphoric extensions, and complicates feminist idea(l)s that focus almost exclusively on identit(ies) by introducing notions of affinity(ies).

\section{The revelation of Asher Levi: A post 9/11 iconographic literacy event}

When attempting to relay artfully the literacy practices employed by and within this group and describe what data suggested about the fragmented selves of each member, autoethnographic writing imposed a distance from the points of revelation members experienced. Writing with the illustrative "I" seemed inauthentic and detached because this technique merely revealed my points of revelation and exposed my struggle with orientation and resolve as a qualitative researcher. When in fact, members' "I" articulations, connections and stances reified their literacies and lifealtering discoveries (Marshall, Staples \& Gibson, 2009; Staples, 2008b, 2008c, in press). To facilitate a way to capture such ruminations, I began to shift and move aspects of member profiles, excerpts from journals, correspondences, emails and transcribed voices in ways that could show, with a type of disordered coherence, the results of analysis and interpretation and portraiture of the selves, literacy practices and epistemological processes of members. Disordered coherence refers to the disorganized ways members cohered their literacy practices and understandings of selves in order to push forward signs of racialized, gendered, spiritual epistemologies. Disordered coherence also refers to the discrepancies the women dealt with over the course of our twenty-two (22) meetings, the nuances of fragmentation that arose when negotiating continually shifting conceptions of self, the notion of our unstable place(s) in a post-9/11 society and our shifting understanding of post-9/11 popular culture narratives.

The result of this approach to data description and transmittal is an unpublished iconographic book entitled The Revelation of Asher Levi: A Woman Reads the World and the Word. I composed the book from the individuated and collective data generated by members. It captures, through its fictitious protagonist Asher Levi, the literacies and epistemologies that emerged in the inquiry. It also features several other dominant fragmented selves. The book is a literacy event (Street, 1993) because it is an iconography - a symbolic, amalgamation of representative selves and a portraiture collection of words, ideas, images and symbols that resists a singular genre. It couches analyzed, interpreted qualitative data assembled by a composite protagonist (Asher) and collaborating characters. Each (re)present other selves and story lived experiences that manifested among members of the inquiry group. The book demonstrates imaginatively and critically one way new literacies theorists might orchestrate a protagonist as a useful literate symbol that facilitates ethnographic inquiry into lived/literate experiences, questions and relationships. What follows is a brief clarification of the function of the data-driven book. The Revelation of Asher Levi functions as an iconographic literacy event in three ways.

The Revelation of Asher Levi acts as a biographical portrait. It serves as Asher's incidental memoir as she portrays critical recollections of life immediately after 9/11. In the book, she chronicles the ways she made sense of her and others' positionalities, influences, subjectivities, and knowledge 
frameworks in relationship to post 9/11 popular culture narratives. She highlights and investigates the post 9/11 musings of her closest friends and discusses the ways her sensibilities (i.e. heightened political awareness, social self-consciousness, personal resolve and a thirst for intimacy and knowing) affect her response to the dissolution of her most significant romantic relationship. It is a coming of age story as Asher discloses to readers the ways she met with several social, cultural, political and spiritual revelations after 9/11 and "grew her self up and out and all over" in the duration (Asher Levi, member journal entry, 05.12.2004). This growth, along with that of her friends, marks a trajectory of awareness and critical sensibilities that affect real change in Asher and compel her to restructure her life and aspirations toward affinities with all people. Asher narrates this plot closely. She presents a window into a life-altering season, one that is crucial to readers' understandings of her development as an African American woman, global citizen, educator, sisterfriend and lover of Black men in the post 9/11 era.

The Revelation of Asher Levi also performs the work of autoethnography. It is a creative, critical text that afforded me opportunities to position artistically many analyzed data and present discussions of their meaning and implications through Asher's voice. ${ }^{1}$ Because I authored the work as a creative scholar, it became a tool for me to situate, trouble, and frame members' post 9/11 literacies and fragmented selves to further the scholarship of new literacy studies, methodology, and our understanding of popular culture as text without speaking exclusively for myself or from my own perspective. In addition, the work helped me to push forward new notions about the ways literacies evolve and perform individuated and communal (r)evolutions for particular purposes such as selfgeneration, -exploration, -determination and -in/exclusion in the post 9/11 era through engagements with popular culture narratives.

Lastly, The Revelation of Asher Levi is a fiction literacy event in that it tells Asher's story on the basis that she and all the characters that thrive from her vantage point are not "real". That is, the work as a whole bends the limits of reality in the ways that certainty is bent in the post $9 / 11$ era-through the construction of illusions, composite voices, fused identities and shifting, interchangeable spaces, messages and signs. So, characters in the work are un-real to the extent that they are archetypical fragmentations of members in the inquiry and the scenarios that members depicted through journal entries, IMs, poems and transcribed conversations. These fragmentations are composed and woven from members' multiple voices, sensibilities and social situations, phenomena that actually manifested and took place among group members within the inquiry.

The Revelation contains the modes of communication actual members used, such as those aforementioned. It also showcases literacy practices used to respond to post 9/11 popular culture narratives and navigate lived experiences shared through fragmented selves. Each character in the book acts as a compounded symbol. Each functions as a vehicle of expression for a dominant fragmented self that emerged within data sets. For instance, Asher, the main character, represents compilations of members' analytical, teacherly selves. Kagan represents their sexual, materialistic, social selves. Laish performs an assemblage of members' wounded, insecure selves. Rajah portrays the women's spiritual, religious selves. Nason consists of members' helping stances; she renders compliance, service and liberalism. Sash and Talon are splinters of the antagonistic, persistently oppositional self. Maven enacts the motherly type; she houses the instances of a loving, maternal self that evolved within each woman in the group. These fragmented selves (i.e. characters of book) were called "sisterfriends" like the women in the inquiry group. This tactic helped to unify "real" 
women with iterations of fragmented selves, further complicating and enriching efforts to realize post 9/11 literacies and knowledge. While I am the sole author of The Revelation and subsequent research articles that feature its excerpts, members helped to name each character, took part in member checks of the amalgamated analyzed data, interpretive codes that organized them, and reviewed some creative descriptions and passages that led to full chapters and a developing plot.

\section{Asher's Intersections with a Post 9/11 Popular Culture Narrative}

The following excerpt from the iconography reveals Asher's musings after a significant breakup. Partly as a result of the impacts of $9 / 11$ and the dissolution of this relationship, she works to build knowledge around what it means to get to "where it's @"1 - a point of destination in knowledge production and resolve toward personal wholeness, which for her, amounts to true love. Asher "writes for her life" (Schaafsma, 1996, p. 110) by tracing the intersections she finds amid encounters with a post 9/11 popular culture narrative that stories the potentially tragic lived experiences of a Muslim woman named Mukhtaran Bibi and those of her sisterfriends. Mukhtaran Bibi was a 28year-old Pakistani Muslim woman who was sentenced to be raped and kidnapped, then denied the opportunity to form her own romantic attachments and marry (Simons, 2002). This sentence was punishment for a crime her brother allegedly committed.

Ms. Bibi wrote about her experiences through personal letters and legal petitions. She also forged oral narratives in protest of her viciously masochistic "punishment". Eventually, she secured justice for herself in the form of physical protection, the right to marry whomever she chose, emotional support, and financial resources to found two same-gender schools that use a progressive Muslim curriculum. Members and I discussed the (r)evolutionary literate life Ms. Bibi generated in the service of her own physical defense, socio-emotional survival, and right to love on her own terms. This post 9/11 popular culture narrative helped us to grapple with some of the ways we conceived and documented conceptions around heterosexual romantic love and began to understand the communicative processes that facilitate sense-making around social and communal affection, affinity and trajectory.

Asher's journal entry pushes forward her critical musings on moving toward a place of revelatory knowledge and wholeness in and after significant relationships by examining closely how Ms. Bibi dealt with the repercussions of relationships that were violently imposed upon her. It evolves Asher's thinking to a critical level because in it she is able to juxtapose the ways Mukhtaran Bibi dealt with "terror" and the ways Asher dealt with "terror" through her local epistemological frameworks. I define "terror" as the private or personal instances of fear that incite negative local repercussions (such as a violent or mean-spirited transaction between strangers or lovers). Local epistemological frameworks are the complex ways of knowing that function at the site(s) of the individual and are shared with members of a similarly situated community. Through the following journal entry, Asher reflects seriously on her deeper understanding of the convergences and divergences of this narrative after $9 / 11$ and the lessons it can teach her about the power of women to affect change in getting to where it's @, regardless of their physical or empirical location and/or herstories. This understanding arises vis a vis Asher's tracings of narrative meeting points within similar sites of struggle shared by local and global women of color. Her local epistemology is founded on the idea that individuals often become lost to the extent that life's journeys may not be

${ }^{1}$ This title will be elaborated on later in the article. 
elected or linear but forced and winding, yet, in any case, we are able to choose how we deal with them, snuff out terror in our midst and incite reverberations of wholeness in and around us.

\section{Getting to where it's @, or, seeing my self in my sister: A revelation of Asher Levi}

Asher Levi: Love is where it's @. If I had learned how to tell him what I wanted and listened to my own voice instead of allowing it to be twisted or silenced, I could have gotten to where it's @ a lot sooner. The point of getting there is to be a better woman - to be a more powerful, more peaceful, loving and joyful woman... all by yourself, first, despite any circumstances. Such qualities depend on individual agency and intimate understanding of one's own road. I'd lost that with him. Maybe I'm being naïve, even unfair. Actually, I probably gave it away. Can't blame somebody else for that. When I tried to set myself straight - my road, my mind, my heart, my body - he was too accustomed to having it his way, to leading the way. He wouldn't relent his footing from where we'd begun. He was the Casanova. I was the fool. He was the cool guy. I was the square. He was the party animal, the fun-loving, hip talking livewire with the slew of fast times and faster women on the side. I was the wannabe wifey who thought she held all the cards. I co-signed the contract, unspoken or not. Sure, he was the asshole. But I wiped the ass. I gave him permission to fake me. I authorized his bad behavior. So, who was to blame?

They say we make the road by walking (Horton \& Freire, 1990). We get to where it's @ by putting one foot decidedly in front of the other. I relinquished my direction in the walk without question and with little consideration of the consequences. It takes two, right? Trying to fix people is hard work. Trying to fix situations is even harder. The toil is long and arduous and it rarely amounts to anything good. It definitely doesn't compare to the peace that comes from surrender. Have you ever tried to make somebody do something they clearly didn't want to do? Ever tried to make somebody into someone you really wanted them to be? Do you know the kind of frustration and heartache I'm talking about? If you even have a hunch then you know that it all seems completely useless. Nonetheless, people persist. There's a lot of brute and subversive force going on in the world. I see it in the stories that surround us.

One reason women of color were [and are] oppressed on the other side of the world is because they feel powerless to change the men who have forced a manipulative and perverse control over their physical, spiritual, social and economic futures. I've detected a similar problem in myself and in every woman I've ever met. Though the circumstances diverge in that few American women are subject to such barbaric, often legalized violations of basic human rights, we are still subject to abuse. It is the abuse we inflict upon ourselves through our own ignorance and lazy acquiescence to the way things are that is a real danger. It is also our stubborn and harmful certainty in individuated strength that invokes hardship. I learned this by watching other women around the world through media, and contrasting their habits of being with my own. For example, a while ago, Rajah contributed an inspiring and provocative story from www.nytimes.com that depicted an instance of terror - one that, in tandem and collection with others like it, could lead to Terror (http://www.nytimes.com/2004/09/29/opinion/29kris.html?_r=1).

The all male tribal counsel of a village called Meerwala sentenced a Pakistani woman named Mukhtaran Bibi to be gang-raped. Her crime? She was the sister of a man who allegedly had an affair with a "high status woman." The man was to be punished by forcing his entire family into shame through the rape of one of his siblings. Mukhataran was chosen. She was gang raped by four men and forced to walk home naked and traumatized in front of 300 villagers. She was expected to commit suicide. However, she did not. Instead, she appealed to Pakistani authorities. She testified against the men who attacked her. The authorities believed her. She was awarded government issued protection and enough money to found two schools in her village - one 
for boys and one for girls. It is likely that she wept and lamented the twisted hand of her fate. At some point, she has probably struggled and been caught in her own mind's jail... fighting against fear, anger, doubt, anxiety, and hopelessness. But her resolve and indignation met with her attachment to triumph and Divine power.

Someone prayed, and is praying, for Mukhtaran Bibi. In addition, she most certainly prayed for herself. If she attempted to fix or figure her neighbors, and the destructive situation she was forced into, she probably would have killed herself. That was the plan from the beginning. Other women in her village had already done so. She was supposed to die. Everything she held dear - her dignity, self-worth, comfort, and honor - were to be stripped from her with every assault suffered by her perpetrators. Invulnerable observers would say that she fixed her own situation, that she affected change in the hearts of a cluster of powerful men who were trained by radical Islamic law to be hardened and calloused against women. Some would attribute her intellect, her will, her influence, or plight as precursors to change. Not so. She was academically ignorant, emotionally and physically battered, of no social importance, and resigned to a village barely named among the modern world. She was, and is, steeped in a cultural milieu that is cemented in fundamentalist Muslim rhetoric. She couldn't do it on her own. The Spirit assisted. It was the Lord who filled the hearts of men who could have sentenced her to death with favor ${ }^{2}$. She prayed. Others prayed. She received grace because she reconciled herself and surrendered her circumstances to the One Greater than herself.

I do not believe we are capable of affecting real, sustained change in our human relationships without Divine guidance or instruction. When I heard of Mukhtaran's story, and the countless other stories of local relational atrocities revealed and forefronted in our consciousnesses after 9/11, I knew there was a connection to my life story and those of the sisterfriends. Somewhere in the maze of stories, we were implicated, nearly entangled, at the very least, paralleled. Of course, I recognized some connections immediately. I had been raped. Until I met with sisterfriends, I don't think I could have even written those words, let alone speak them out loud. It was before my ex. It was my time of anonymity. I had no footing in my own realm of self. Although I could boast of education, status, wealth, and standing, I was not as brave as Mukhtaran Bibi. I didn't voice my rage to the Lord. I didn't ask for guidance. I didn't seek a plan from the Spirit or seek retribution through earthly authorities. I hid. And, in my own sad way, I almost killed myself with withdrawal, self-pity, and isolation... primal seeds of terror. My death inched in slowly through the pinhole of silence and lying by omission. I did not scream from the rooftops as Ms. Bibi did. I did not petition an arrest. I did not demand protection and retribution. Yet, by outward appearances, I had some authority. Mukhtaran Bibi did not. Or, did she?

Upon deeper investigation I find that the conclusions are not as obvious as I originally thought. Without degrees, pedigrees, riches, or agency, Ms. Bibi travailed her plight and proved victorious in tangible ways. She got to where it's @. With all my comforts and acquisitions, I had not. I harbored my offenses internally for years. There were multiple points of departure for us as women, worlds apart, in the midst of these terrorist attacks. But the definitive one is this: she moved forward to her destination; she prayed; she took the risk. I did not. I received mercy by virtue of my humanity, and so, I did not perish. She received grace by virtue of her appeals, and so, she thrived.

While I hadn't fully realized the power of prayer in human relationships the night I was raped, nor did Maven realize it when she was molested as a child, neither did Sash and Talon on the respective cold winter mornings when they had their abortions, the revelation of prayer and conciliatory movement toward wholeness was not completely lost to us. Thankfully, we began to remember prayer as an active staple from our youth when our eyes met each other's in the cyclical mirrors we held up to our selves. The days and nights I spent imprisoned 
in my own mind should not, could not, be compared to the degrading experiences of Mukhtaran Bibi. Comparison and contrast are not at issue. The point is to find a degree of overlap and understanding in the entanglement of post 9/11 narratives as unifying, human stories. It is to connect seemingly disparate narratives, so that we can understand better how we fit into the big chronicles of our post 9/11 world... it is to set our feet on solid ground in the midst of change and understand better how to get to where it's @.

Reading the worlds of the women and men around the globe who participate in relationships, by design or by force, helps us to better discern the smaller bits of terrorism that insight the catastrophic ones (Terror). The sisterfriends have learned that there is no bigger crisis in the world than the individual one, festering in our own minds, in our own hearts, threatening to explode and annihilate our selves. When I cried so that the tears washed across my face and I trembled and moaned and lulled myself into unconsciousness, I could not hear of another person's plight. I was fighting my own war for survival. So, comparison is pointless. It is in the moment that our terror threatens to cut at our lives, and catastrophically affect the lives of others, that reflection is needed. How can we better grasp our own power when we're constantly giving it away or having it stolen...never getting to where it's @? We've learned that we have to communicate with God. We have to stop trying to control everything on our own. If we include divinity and a commitment to social and global justice while we are in the midst of our relationships (be they forced or of our own design), life devoid of terror is reified as not only possible, rather, it leans toward probable. But, first, an examination of real life relationships is necessary. We have to be sure not to take each other in directionless places while we do the lookinglisteninglearningloving. And we have to be walking in the same general direction, perhaps in different ways, but always, together.

\section{On the revelations of fragmented selves and post 9/11 literate lives}

When members in the inquiry employed new literacies in the teaching/learning spaces of their personal lives to explore and respond to representations in post 9/11 popular culture narratives, they assembled a system by which they could locate selves and deal with the dissonance and perplexities that arose when confronted with contrary conceptions of selves or selves' responses, language, behavior and/or phenomenological understanding of post 9/11 narratives. This system was devised from a convergence of literacy practices that occurred in relationship to fragmented selves. That is, members were able to read, write, speak and listen in culturally comfortable and socially situated ways that afforded them insight into facets of their being and those of others, especially those that were uncomfortable and disruptive of conscious ideal selves (i.e. one steeped in perceptions of wholeness). I identified selves as they emerged among members. Each self permeated others to varying degrees, as fragmented selves are disjointed, porous and frequently concentric. When coming to grips with representations storied within post 9/11 popular culture narratives, like that of Pakistani women survivors of rape, and wondering through the ways terror impacted or posed implications for fragmented selves, the women used a tactic I call "enmeshing".

This tactic asked members to "see [them] selves in every person" (Staples, Whole Group Transcript, 11.12.2003). It required that members speak or write responses to/for/about "others" as if they were kindred. In addition it asked that whenever possible, members read, write, speak and/or listen on a deeper level, as if the "other" was self. Enmeshing gave way to the concept of "terror" as a seed of Terror. It helped members to become aware of the ways local, intrapersonal disruptions and grapplings with fear fester and, when presented with extraordinary circumstances, can be positioned to devolve to Terror. It also gave voices to fragmented selves, providing me a means with which to write them. This awareness elucidated points of intimate connections between and 
among individuals subjectified within post 9/11 narratives who at first glance appeared disconnected from members' selves by class, ethnicity, nationality, religious affiliations, region and language. It also helped sisterfriends to read connections between and among each other, as depicted in Asher's quest to discover connections with her critical perceptions about getting to

where it's @. She accomplished this by locating and examining closely similar experiences within a post 9/11 narrative.

The poetry in the prose

Objects called 'poems' are sites of literary production where language also is an actor [in]dependent of intentions and authors; bodies as objects of knowledge are material-semiotic generative nodes. Their boundaries materialize in social interaction. Boundaries are drawn by mapping practices. Objects do not preexist as such. Objects are boundary projects. But boundaries shift from within; boundaries are very tricky... a risky practice.

(Haraway, 1988, p. 579)

Asher Levi, the analytical, teacherly self, functioned as the protagonist and sense-maker for other selves in the iconographic book. Members chose her full name because it means "happy, blessed" and "united, joiner", respectively. "Levi" was also the name of Jacob's (the Hebrew patriarch) third son, who was named and assigned all the leadership duties of a high priest of Israel. Asher compiled the poetic phrase where it's @ from the ruminations and sayings of multiple selves. These included, for example, highlighted risings of the wounded self (Laish) within the person of the material/sexual/social self (Kagan), through the voice of her self (Asher as analytical teacher). This mode of communication helped to demonstrate how members became aware of the ways their responses to personal and post 9/11 narratives splintered with respect to selves and functioned to collapse the "risk...boundary project" Haraway describes. When considering ways to draw and play with boundaries by mapping practices, generating sights of literary production with iterations of selves became an important strategy. The cultivation of poetic devices then, was crucial to the processes of employing literacy practices and voicing/writing fragmented selves. Considering where it's @ as a point of knowledge production and destination for wholeness arose in relationship to the creative, poetic use of language as an actor [in]dependent of intentions and authors (Haraway, 1988). As Haraway suggests, this play with boundaries and directions is tricky. It means that negotiating where it's@ includes "materializing social interactions" between bodies and language variations. Such processes are complicated because they are inherent in voices of fragmented selves and function through fragmented narratives - ever shifting, slippery phenomena and uniquely post 9/11.

Asher pursued where it's @ by cohering a collective vision of what it looks like and includes. Asher relayed the sisterfriends' understanding of this destination by marking a balance of (un)desirable occurrences, expectations, hopes and tensions between and among a man and a woman in relationship with each other. In addition, she employed her literate abilities to articulate and record the truths of herself as it manifested in relationship to revelations about personal and post 9/11 narratives. These included the idea of being "out there," exposed to the elements of life and longing for refuge and a true friend (Staples, in press). They also included transactions with "admission and reconciliation" (Staples, in press). The overall expression of Asher's writing includes the idea of multiple truths contained within one voice and "arrivals" - the advent of destinations in knowledge production. The recurrences of these literate markings also introduced elements of 
critical consciousness into engagements with popular culture narratives. They helped to craft responses to the why and how of members' motivations and distinguished components of epistemological intensities. Asher's critical response to Muhataran Bibi's story worked to strike down delusions and allusions to "get @ what is real" (i.e. a relatively stable and unifying truth). This work was a procedure; it helped to position and locate her as the teacherly fragmentation, reveal dangerous and paradoxical combinations as "contradictory and necessary" (Haraway, 1988, p. 579) and connect to seemingly distant experiences with global terror by locating experiences with terror inside her own experience.

As chapters of The Revelation of Asher Levi were drafted, group members provided feedback as I decided how to show visually their literacy practices. Within the context of journal entries (and other modes of communication such as IMs and emails), members manipulated the mechanics of technology to (re)present their understandings and conclusions. These manipulations included use of various fonts, the bold, italics and underline functions in Microsoft Word ${ }^{\circledR}$, as well as the infusion of hyperlinks, color, emoticons and sketches. These visual illustrations are significant and help to convey certain feelings such as foreboding or fright. Or, power through interjection of the font "Impact" to spell the words where it's @. Such illustrations demonstrate the choices available to members and the ways they were taken up to frame their direct attention to the nuances of their post 9/11 literate lives.

\section{The prose}

The cyborg is likened to the political identity of "women of color," which marks out a self-consciously constructed space that cannot affirm the capacity to act on the basis of natural identification, but only on the basis of conscious coalition, of affinity, of political kinship. (Haraway, 1988, p. 599)

Writing the fragmented selves of women in the inquiry included delineating a "self-consciously constructed space" that could affirm the capacity to act on the basis of "conscious coalition, affinity and political kinship" (Haraway, 1988, p, 599). The contexts that situated members' selves affected the manifestations of selves and the literacy practices that communicated their knowledges. Members' responses to post 9/11 narratives were communicated increasingly through personal, hyper-communicated, multimodal literacy practices. When writing prose (i.e. journal entries like the one herein), Asher often created an interplay of closeness to and distance from representations and stories within and about post 9/11 narratives. This dance was intended to try out objective and subjective views on what was happening, pictured, or communicated. It was also intended to find ways to securely situate the emergence or transformation of knowledges through a closeness that can be found within and between women. In order to couch such practices in a safe place, the varied teaching/learning spaces of our personal lives were all ascribed with an ethos of peace, acceptance and safety.

To articulate this, we adopted the stance of Anna Julia Cooper, a critical Black feminist foremother, who said, "when and where I enter, in the quiet, undisputed dignity of my womanhood, without violence and without suing or special patronage, then and there the whole race enters with me" (Giddings, 1984, p. 2). This stance encouraged the propagation of critical literacies, responses to post 9/11 popular culture narratives and the exercising of fragmented selves in the service and integrity of Blackness and sisterhood within any and all contexts, from actual to virtual. It encouraged a move beyond racialized and gendered identities and ways of being to experiences 
with affinities among the actual women in the inquiry. These ways of being transferred to, and showed up within, iterations of fragmented selves. This meant that our situated knowledges were uniquely Black, critical, feminist and steeped in intimate relationships. It also meant that they were purposed.

The coalition, affinity and political kinship that Asher came upon when placing pieces of sisterfriends' narratives adjacent to Mukhtaran Bibi's arose through inquiry and deference. Asher inquired into Mukhtaran's story and wondered about the ways her experiences with terror held points of similarity and sisterenergy with the ones close to her heart (i.e. those that emerged within sistercircles). This choice was intentional and reflective of the focus among sisterfriends. When Asher deferred to Mukhtaran's exercise of wisdom and faith she connected it to the power of prayer. This connection revealed not only another point of affinity-in addition to the subjugation of women through brutish attempts to control the female body with sexualized intimidation (molestation), pain (abortion) and humiliation (rape)-it also situated the knowledge of fragmented selves intimately with Mukhtaran's. This connection helped to elucidate prayer as a powerful narrative practice, yielding certain and desirable fruits. This made coalition, affinity and political kinship possible. This "self-consciously constructed space" for writing the production of knowledge showed the "cyborg" identity of the women in the inquiry via the voices of fragmented selves. This political identity was assigned to the service of the revelation of selves for personal serenity, critical social and political consciousness, and local, interpersonal activism that might resound through individual and collaborative efforts positioned to serve the greater good.

\section{Implications for new literacies research and teaching}

Hemmingson (2008) presents a call to action for what he terms the Eighth Moment in qualitative research and notes that we "must find (or create) a method that best suits each lived experience" and "rebels against the colonists of social science" (p. 1). I find his call particularly crucial to the work of understanding dynamically the literate lives of marginalized individuals and groups in relationship to fragmentations and post 9/11 popular culture narratives. The findings presented here speak to a dearth in research among this group and simultaneously point to a scarcity of deep thought about the ways literacy practices become critical and (r)evolutionary-both pointedly resistant and concessional and evolving over time, for particular purposes and with profound respect for spirituality, gendered, racialized community members and humanity at large in current times and with relationship to fragmented selves. Contemporary new literacies research in the post 9/11 era must attend closely to the socially situated ways individuals and groups incorporate and use selves and identities to build and share knowledge about myriad local and global narratives. Since teaching/learning contexts are shifting and evolving to include web 2.0 spaces and new technologies with global influence, literacy practices are framed with new issues of location, transference and agency. In addition, these factors pave the way for that which is critical in new literacies, pointing to new literate lives that intersect issues of social (in)justice as they bump up against and traverse "others". For instance, the African American women in the inquiry group discussed here rallied around a sense of critical, spiritual, Black feminine pride as they engaged narratives (Marshall, Staples \& Gibson, 2009; Staples, 2008a, 2008b, 2008c, in press).

The culmination of the selves that emerged from the group drew attention to this activist stance as it became at once personal, public, and useful in determining one's location and propensity for constructive action in the post 9/11 era. Members employed post 9/11 literacies to explore and 
respond to post 9/11 popular culture narratives. And, their fragmented selves were written through these literacies. They:

- Integrated fragmented selves (and other iterations of identit(ies) within each others' homes, other familiar spaces, and hyper-communicative teaching/learning contexts for knowledge production

- Intersected personal narratives and post 9/11 popular culture narratives as a means for knowledge production

- Fragmented narratives to reflect complexities within knowledge engagements and production

- Integrated both individuated and communal stances on selves and narratives to build knowledge

- Constructed multiple contexts to couch knowledge production, interpersonal relationships, intimacies and new knowledge

- Introduced spiritual/religious epistemologies to support new knowledge

- Accessed racialized and gendered perspectives on both local and global narratives to generate and affect change in knowledge development

- Introduced language play and manipulation of digital print aesthetics and mechanical tools to relay new knowledge

- Heightened critical consciousness about consequential reverberations of 9/11 and social, cultural, religious, political and economic occurrences and intersections world-wide

As importantly, the above post $9 / 11$ literacies paved a way for sisterfriends to draw stronger connections to women of color within their immediate social situations and those in global contexts. The women drew strength from reading the way Mukhtaran Bibi navigated her situation, against gross intergenerational religious and political injustices against women. They noticed intently the methods of reading, writing, speaking and listening other women of color perpetuated in the service of knowledge production and civil action against terror. This stance was a subversive citation. It demonstrates a sense of agency and was a result of the members' text engagements. They chose to hone in on the post 9/11 PCN, understand it from their own vantage points and move beyond its assumptions, particularly as they intimated their own parameters as sympathetic readers/writers/speakers/listeners. Their readings honed in on successes highlighted in the post 9/11 PCN and traced them to a lifelong mission in which Mukhtaran Bibi constructed a defiant response to blockades barring her from getting to where it's @ by reading/writing/speaking/listening to and against the terror of rape and subjugation as a local and global leader. Such triumphs were accomplished through her confrontation and exposure of extremely conservative men and their "perpetuation of the segregation of women" (Simons, 2002, para. 24). This and other post 9/11 narratives pointed sisterfriends to new knowledge about the unique, profound impact and influence of feminine power through sisterhood, mothering, partnership and affinity (if not for this truth, the perpetual segregation and oppression of women would be deemed unnecessary and ignored among domineering men worldwide).

Issues of power and positionality among the sisterfriends were also explored within the women of the inquiry. When considering whether or not we qualified as "marginalized" people, given our high levels of education and economic statuses particularly in relationship to the often uneducated and economically vulnerable women storied in most of the post 9/11 narratives we engaged, we 
determined that, like our Black and Brown sisters in many nations, we are marginalized to the extent to which we are caught up in the gazes and articulations of members of dominant groups, or those individuals and groups whose power is chronically yielded or to which power is routinely deferred (Staples, in press). As a result, in various contexts occupied or dominated with ideologies enabled by uniquely valued persons, African American women's knowledges, positionalities and relationships (like those of other women of color) are severely questioned and/or considered unreasonable, unhelpful or underdeveloped. The idea of marginalization was not, at the time, considered countermanding to the orienting conceptual framework of fragmentation. Instead of understanding marginalization as a unified, singularly labeled space from which to make meaning and encounter (new) knowledge, and therefore, contradictory to the plural concept of fragmentation, the term was taken back from the repertoire of the oppressor, as hooks proposes $(1989,1992)$. Instead, it was understood as a dynamic, multiplicitous vantage point from which to do literacy work and form literate lives. The members' consideration of themselves as "marginalized," in tandem with other storied women in the post 9/11 era, could then be seen, and understood, through their fragmentations, as valuable to literacy work and empiricism (Staples, in press).

It is important to note then, that, in alternative contexts, through othered lenses, unusual articulations, and new narratives, "marginalized" people (including African American women) are repositioned and newly understood in terms of our inherent power and we are respected differently. This type of marginalization carves out a potential point of connection to the lived experiences and fragmented narratives of Black and Brown people locally and globally. As the post 9/11 era becomes more complicated via the conflation of multiple worlds, narratives, identities, class structures, language systems and religious doctrines while promoting beliefs for public consumption, new literacies theorists must interrogate the boundaries of literate lives, particularly with regard to technology and PCNs. Such interrogations allow points of entry into these lives. de Freitas and Paton's (2009) remaining questions regarding fragmented selves instigate the next phase in future inquires. They ask, "How do you imagine your reader? Do you imagine a unitary reader resonating with your narrative? Do you imagine a reader in pieces? To whom do we write these narratives? Who do they serve?" (de Freitas \& Paton, 2009, p. 487). These questions poise future work and spur new possibilities for the field of qualitative research, and particularly among new literacies theorists, scholars and practitioners.

The questions not only push forward new literacies research in the post 9/11 era, they also point to the ways teachers may be prepared to include post 9/11 literacies within traditional teaching/learning spaces inside schools. As youth become more tech-able and simultaneously conscious about issues of local and global (in)justices that can be traced to 9/11 (such as the collapse of the U.S. financial systems, the U.S. presidential election of Barack Hussein Obama, the wars on Terror in Iraq and Afghanistan, the absence or prevalence of popular culture narratives on death, maiming and recovery among soldiers and citizens, etc.), classroom teachers must learn to include space and time to contend with the fragmentation of selves, narratives and knowledge production in the post 9/11 era (Staples 2008a, 2008b, in press). Since post 9/11 literacies coalesce racialized and gendered epistemologies, occur in multiple contexts, perform the work of knowledge production and sharing and are interdependent with(in) interpersonal relationships (be they "real" or contrived online), literacy educators should: 
- Consider the ways technologies, modalities, local and global narratives intersect and inspire new knowledge

- (Co)create with students opportunities to integrate post 9/11 popular culture narratives into classroom reading experiences, written assignments and oral debates

- Attend closely to the ways fragmented selves rise up and/or are arrested when encountering these narratives and reflect on the implications of these occasions

- Hone in on one's own pedagogical and personal understanding of post 9/11 PCNs and literacies as a facilitator and assessor of knowledge

In addition, classroom teachers may consider new questions about contemporary literate lives. Such questions expand de Freitas and Paton's (2009) list. As we prepare teachers and support youth to engage with the prevalent and weighty content and notions of the post 9/11 era we may ask of all who read/write/speak/listen: How do you imagine your self as a reader/writer/ producer/contributor in the post 9/11 era? Do you imagine unitary or disparate selves resonating with(in) your narrative(s)? Do you imagine a reader/writer/ speaker/listener in pieces? To whom do you write your post 9/11 narratives? Who do they serve? Who do they exclude? Subjugate? Empower? How do you know? Why does it matter? (Staples, in press).

\section{References}

Anderson, L. (2001). Autobiography. New York: Routledge.

Barton, D., \& Hamilton, M. (2000). Literacy practices. In D. Barton, M. Hamilton, \& R. Ivanic (Eds.), Situated Literacies: Reading and Writing in Context (pp. 7-15). New York: Routledge.

Collins, P. H. (1990). Black feminist thought: Knowledge, consciousness and the politics of empowerment. New York: Routledge.

Davies, B., Dormer, S., Gannon, S., Laws, C., Taguchi, H. L., McCann, H., et al. (2001). Becoming schoolgirls: The ambivalent project of subjectification. Gender and Education, 13: 167-182.

de Freitas, E. \& Paton, J. (2009). (De)facing the self: Poststructural disruptions of the autoethnographic text. Qualitative Inquiry, 15 (3): 483-498.

Denzin, N. K., \& Lincoln,Y. S. (2000). The seventh moment: Out of the past. In N. K. Denzin \& Y. S. Lincoln (Eds.), The Handbook of Qualitative Research (2nd ed., pp. 1047-1965). Thousand Oaks, CA: Sage.

Dillard, C.B. (2000). The substance of things hoped for, the evidence of things not seen: Examining an endarkened feminist epistemology in educational research and leadership. International Journal of Qualitative Studies in Education, 13 (6): 661-681.

Ellis, C. (2004). The Ethnographic I: A Methodological Novel about Autoethnography. Lanham, MD: Altamira Press. 
Ellis, C., \& Bochner,A. P. (2000). Autoethnography, personal narrative, reflexivity: Researcher as subject. In N. K. Denzin \& Y. S. Lincoln (Eds.), The Handbook of Qualitative Research (2nd ed., pp. 733768). Thousand Oaks, CA: Sage.

Giddings, P. (1984). When and Where I Enter: The Impact of Black Women on Race and Sex in America. New York, NY: W. Morrow.

Haraway, D. (1988). Situated knowledges: The science question in feminism and the privilege of partial perspective. Feminist Studies, 14 (3), 575-599.

Heath, S.B. (1982). Protean shapes in literacy events: Ever-shifting oral and literate traditions. In D. Tannen (Ed.), Spoken and Written Language: Exploring Orality and Literacy (pp. 91-117). Norwood, NJ: Ablex.

Hemmingson, M. (2008). Here come the naval gazers: Definitions and defenses for auto/ethnography. Social Science Research Network. Retrieved from http://ssrn.com/abstract=1099750

hooks, b. (1989). Talking Back: Thinking Feminist, Thinking Black. Cambridge, MA: South End Press.

hooks, b. (1992). Black Looks: Race and Representation. Cambridge, MA: South End Press.

Horton, M. \& Freire, P. (1990). We make the road by walking: Conversations on education and social change. Philadelphia: Temple University Press.

Marshall, B., Staples, J. M., \& Gibson, S. (2009). Ghetto fabulous: Reading representations of Black adolescent femininity in contemporary urban street fiction. Journal of Adolescent and Adult Literacy, 53 (1): $28-36$.

Peters, M., \& Burbules, N. (2004). Poststructuralism and Educational Research. Lanham, MD: Rowman \& Littlefield.

Schaafsma, D. (1996). “Things we can't say: Writing for your life and stories in English education. Theory into practice: Situated Pedagogies, 35 (2): 110-116.

Siedel, J. V. (1998). Qualitative data analysis. Qualis Research. Retrieved from $\mathrm{ftp}: / / \mathrm{ftp}$.qualisresearch.com/pub/qda.pdf

Simons, M. (2002, November 9). Behind the veil: A Muslim woman speaks out. The New York Times. Retrieved from http://www.nytimes.com

Staples, J. M. (in press). “Where it's at": African American women's resolute love poetry through new literacies. Journal of Curriculum and Pedagogy, 7 (2):, 6-16.

Staples, J. M. (2008a). "Do you remember?": Confronting post-9/11 censorship through critical questioning and poetic devices. English Journal, 97 (5): 81-87. 
Staples, J. M. (2008b). "How do I know what I think 'till I hear what I say?": The role of collaborative discourse in critical media literacy development. The International Journal of Learning, 15 (7): 107-118.

Staples, J. M. (2008c). "How does that hurt?": Encouraging teacher leadership that confronts linguistic violence in popular culture media. English Leadership Quarterly, 31 (2): 3-6.

St. Pierre, E. (1997). Circling the text: Nomadic writing practices. Qualitative Inquiry, 12: 403-417.

St. Pierre, E. (2000). Working the Ruins: Feminist Poststructural Theory and Methods in Education. New York: Routledge.

Street, B. (1993). Introduction: The new literacy studies. In B. Street (Ed.), Cross-Cultural Approaches to Literacy (pp. 1-21). New York: Cambridge University Press.

\section{Author}

Jeanine M. Staples, Ed.D is Assistant Professor of Language and Literacy in the Department of Curriculum and Instruction at The Pennsylvania State University. Email: staples@psu.edu

\section{Notes}

${ }_{1}^{1}$ Asher's voice does not represent the voice of the author of the book and this article. Asher is a fragmented self, as are all other characters in the book. Asher's voice was employed as narrator and protagonist because she emerged as the teacherly self and was apt not only to transformations within the post 9/11 era but also able to navigate and explicate literacies and effects of selves from the stance of an educator.

${ }^{2}$ Proverbs 21:1. 